
Passiflora genus, its importance of pharmacy and investigation of the samples which is sold by passiflora
(çarkıfelek) name in the market of Turkey

\author{
Erkan Can KÖSE *1, Ayşegül KÖROĞLU ${ }^{1,2}$ \\ ORCID: 0000-0003-3491-6079; 0000-0002-8450-1376
}

${ }^{1}$ Ankara Üniversitesi, Eczacılık Fakültesi, Farmasötik Botanik Anabilim Dalı, 06100 Tandoğan-Ankara, Turkey

${ }^{2}$ Afyonakarahisar Sağlık Bilimleri Üniversitesi, Eczacılık Fakültesi Farmasötik Botanik Anabilim Dalı, Turkey

\begin{abstract}
Recent studies on the conventional use, chemical composition and biological effects of Passiflora incarnata, $\mathrm{P}$. alata, P. edulis and P. caerulea species which have entered our country's market with fruits in recent years that are grown as climbing plants at the edges of parks and gardens and have medical value, which belong to Passifloraceae family and have economic value, have been carried out in our study. The experimental part of the study was carried out for the diagnosis of drugs known as "passionflower" or "passiflora", which are not naturally grown in our country but are consumed especially for sedative purposes and presented to the public for this purpose. In the capital city of Turkey, Ankara, 3 samples that are sold under the name of "passionflower" or "passiflora" were purchased and examined. As a result of the study, the two of them are determined as Paliurus spina-christi Mill. (garland thorn; Rhamnaceae) fruits. The third sample that sold as "passiflora" or "passionflower root" is found out to be the fruits of Caiophora lateritia Klotzsch (Loasaceae), a plant that does not grow in our country and belongs to the Middle Andes Mountains. These findings show that the "passiflora, passionflower" samples which are sold in Ankara market do not obtain the correct plant and the plant parts.
\end{abstract}

Keywords: Passifloraceae, Passiflora alata, Passiflora edulis, Passiflora incarnata, Paliurus spina-christi

\title{
Passiflora cinsi, eczacılıktaki önemi ve Türkiye piyasasında passiflora (çarkıfelek) adı ile satılan örneklerin incelenmesi
}

\section{Özet}

Çalışmada, ülkemiz piyasasına son yıllarda meyveleriyle de giren, park ve bahçe kenarlarında sarılıcı, tırmanıcı bitki olarak yetiştirilen ve tıbbi değeri olan, Passifloraceae familyasında yer alan, ekonomik değere sahip Passiflora incarnata, P. alata, P. edulis ve P. cearulea türlerinin geleneksel kullanılışı, kimyasal bileşimi ve biyolojik etkilerinin son yıllarda yapılan çalışmaları derlenmiştir. Çalışmanın deneysel kısmı, ülkemizde doğal olarak yetişmeyen ancak özellikle sakinleştirici amaçla tüketilen ve bu amaçla halka sunulan "çarkıfelek" ya da "passiflora" adıyla bilinen drogların teşhisine yönelik olarak yürütülmüştür. Başkent Ankara'da "passiflora" veya "çarkıfelek" adı ile satılan 3 örnek satın alınmıştır. Yapılan çalışmalar sonucunda ikisinin Paliurus spina-christi Mill. (karaçalı; Rhamnaceae) bitkisine ait meyveler olduğu saptanmıştır. "Passiflora" ya da "çarkıfelek kökü" adıyla satılan üçüncü örneğin ise ülkemizde yetişmeyen, Orta And bölgesine ait bir bitki olan Caiophora lateritia Klotzsch (Loasaceae) meyveleri olduğu tespit edilmiştir. Elde ettiğimiz bu bulgular, Ankara piyasasında satılan "passiflora, çarkıfelek" örneklerinin doğru bitkiden elde edilmediğini ve drog olarak satılan bitki kısımlarının doğru olmadığını göstermiştir.

Anahtar kelimeler: Passifloraceae, Passiflora alata, Passiflora edulis, Passiflora incarnata, Paliurus spina-christi

\footnotetext{
${ }^{*}$ Corresponding author / Haberleşmeden sorumlu yazar: Tel.: +902722463301; Fax.: +902722463301; E-mail: eczacilik@ afsu.edu.tr

(c) Copyright 2021 by Biological Diversity and Conservation Geliş tarihi: 23.10.2020; Yayın tarihi: 15.04.2021 BioDiCon. 933-1120
} 


\section{Giriş}

Passifloraceae Juss. ex DC. bilimsel sınıflandırmada Violales ordosu, Magnoliopsida sınıfı ve Magnoliophyta alt bölümünde yer alır. Passifloraceae'nin yaklaşık 700 tür içerdiği düşünülse de bu sayı, tür varyasyonları ve taksonomik belirsizlikler nedeniyle kesin değildir [1-3].

Passifloraceae, çok değişken yaprak ve çiçeklere sahiptir. Tendriller (tırmanıcı sürgün) ile gelişen sarılıcı ya da tırmanıcı otsu veya tendrilleri olmayan çalı veya ağaç formunda tropikal bitkileri kapsar. Yapraklar basit veya nadiren bileşik, alternan, stipulat, petiol salgılı (2-10) ya da salgısı, lamina basit veya 2-3-5-9 loblu, kenarı düz ya da serrat, genellikle salgı taşır. Çiçek durumu aksiller, simoz, sesil veya pedunkulat, primer eksen genellikle bir tendril taşır; sekonder eksen genellikle kısalmıştır; brakteler şeritsi, lanseolat veya yaprağımsıdır, bazen salgı taşır; pedisiller artikulattır. Çiçekler aktinomorf nadiren zigomorf, hermafrodit veya tek eşeylidir; periant kalıcı, periant parçaları serbest veya tabanda birleşiktir, genellikle kupa şeklinden tüp şekline kadar değişen hipantiyum kırmızı, pembe, leylak, mor, mavi, yeşil, beyaz, nadiren de sarı renklidir; sepallerin sayısı genellikle 5 olmakla beraber 3-6 arasında değişebilir, petallerin sayısı sepallerinki ile eşittir, imbirkat, nadiren bulunmaz; korona 1 veya çok sayıda filamentli; stamenler 4 (bazen 5), androginofor üzerine bağlanmış, anterler dorsifikstir. Ovaryum (1-) 3 (-5) karpelli, üst durumlu, tek gözlü, androginofor üzerinde uzanmış sesil veya stipitattır, plasentasyon parsiyal, övül çok sayıdadır; stilus (1-) 3 (-5), serbest veya tabanda birleşmiştir; stigmalar küremsi, kapitat, papillat veya parçalı. Meyve bakka veya 3-5 valfli lokulisit kapsüldür. Tohumlar tek veya çok sayıda, yassılaşmış şekilde, hafif eliptik, retikulat, foveolat, çukurcuklu veya enine olukludur; endosperma zengin, kotiledon yaprak şeklindedir. Çiçekler genellikle gece açar ve gece açan çiçeklerde tozlaşma yarasalar ile sağlanır $[2,4]$.

Passiflora L., Passifloraceae familyasının yaklaşık 520 tür içeren en büyük cinsidir. Cins P. subg. Astrophea, P. subg. Decaloba, P. subg. Passiflora, P. subg. Tetrapathea ve P. subg. Deidamioides olmak üzere beş alt cinse sahiptir. Passiflora tırmanıcı, çalımsı-otsu formda, çok yıllık bitkileri içerir. Genellikle Amerika kökenlidir, ancak Asya, Afrika ve Avustralya'da da yetişmektedir. Cins ekonomik değere sahip birçok tür içerir. Cinsin değişik türleri gıda [Passiflora edulis Sims. (Resim 1); P. laurifolia L.], tedavi [P. edulis, P. alata Dryand, P. incarnata L. (Resim 2)] ve süs [P. caerulea L.] amaciyla kullanılmaktadır. P. alata ve P. incarnata (Resim 2) Homeopatik Farmakopeler (DHA 1978, HPUS 1992) de dâhil olmak üzere birçok ülke Farmakopesinde (EP 2013, TF 2017) ve değişik monograflarda (EMA 2013, ESCOP 2003, FFD 2017) özellikle, sedatif ve anksiyolitik etkisi nedeniyle insomnia ve anksiyete gibi santral sinir sistemi hastalıklarının tedavisinde kullanıldığ 1 için kayıtlıdır [1-3, 5-16]. Cinsin ülkemizde doğal olarak yetişen türü olmamakla beraber P. caerulea (Resim 3, 4), güzel ve gösterişli çiçekleri nedeniyle özellikle peyzaj düzenlemelerinde süs amacıyla kullanılmaktadır.
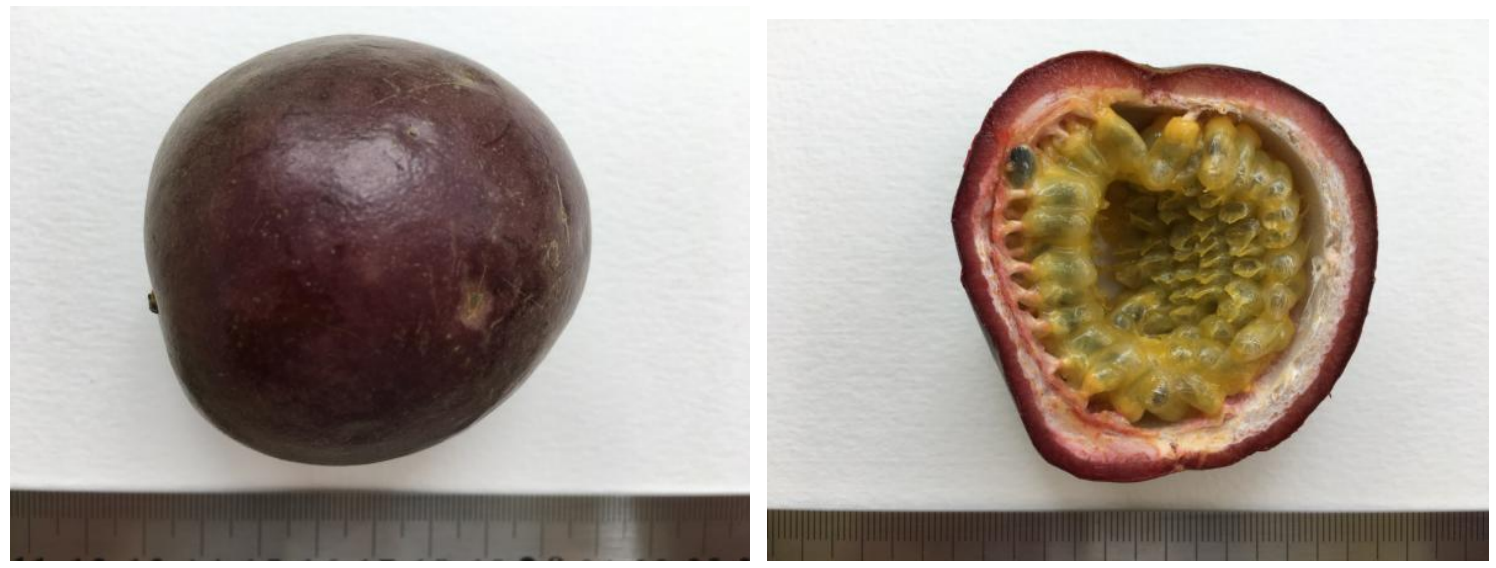

Resim 1. Passiflora edulis meyve (Foto: Ayşegül Köroğlu)

Bu çalışmada, cinsin en çok bilinen üyelerinin kullanılışı ve biyolojik etkilerine ait son yıllarda yapılmış çalışmalar derlenmiştir. Ayrıca ülkemizde doğal olarak yetişmeyen ancak Türk Farmakopesi 2017'de [7] kayıtlı olan ve piyasada "çarkıfelek veya passiflora" adı ile satışa sunulan örnekler piyasadan satın alınmış ve bu örnekler elde edildikleri bitki kaynağı, drog özelliği, saflık kontrolü açısından incelenmiştir. Ayrıca piyasadan temin edilen bu örnekler halk sağlığında tedavi edici özellikleri açısından değerlendirilmiştir. 


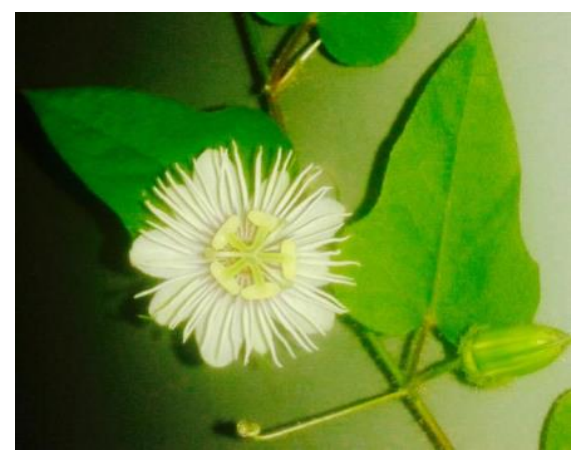

Resim 2. Passiflora incarnata, beyaz çiçekli (Foto: Ysabel Campos Santaela, Venezuella)

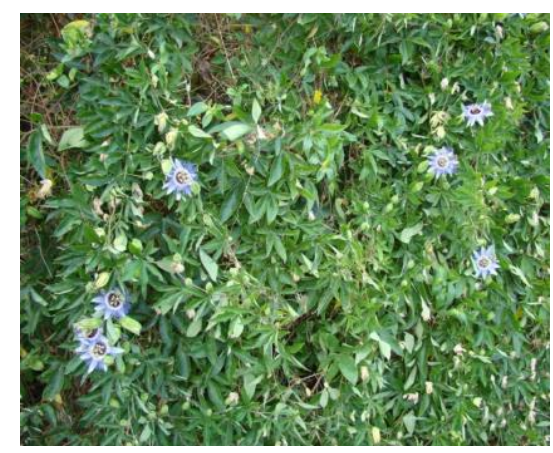

Resim 3. Passiflora caerulea (Foto: Ayşegül Köroğlu, Samsun)

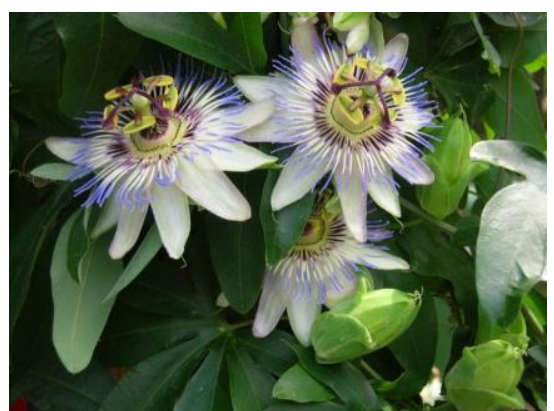

Resim 4. Passiflora caerulea (Foto: Ayşegül Köroğlu, Samsun)

\subsection{Genel Bilgiler}

\subsubsection{Geleneksel Kullanım}

Passiflora L. cinsinin bazı türleri dünyanın çeşitli toplumlarında geleneksel olarak hipnotik-sedatif amaçla kullanılmaktadır. Avrupa'da insomnia (uykuya dalamama ya da gece boyunca sürekli uyuyamama) ve anksiyetenin (nedeni belli olmayan tedirginlik, kaygı, korku, gerilim, sıkıntı hali) tedavisi için kullanılır. Kuzey Amerika'da sedatif olarak geleneksel kullanıma sahiptir. Ayrıca Brezilya'da analjezik, antispazmodik, antiastmatik, sedatif amaçlarla; Irak'ta narkotik ve sedatif; Türkiye'de nevralji, nöroz (asteni, saplantı ve histeri gibi bir grup uzun dönemli ruhsal hastalıklara verilen genel bir terimdir), insomnia, epilepsi, dismenore gibi rahatsılıkların tedavisinde; Polonya'da histeri ve nevrasteninin (sinir sistemi fonksiyonunda olan aşırı çalışma nedeniyle oluşan zayıflık ya da bitkinlik durumu) tedavisinde; Amerika'da diyare, dismenore, nevralji, yanıklarda, hemoroid ve insomnianın tedavisinde kullanılır. Ayrıca Hindistan'da opiyat bağımlı kişilere tedavi amacıyla uygulanır [5,6,11,14].

Passiflora alata, Brezilya'da ekonomik değere sahiptir ve Brezilya Farmakopesi'nin 5. yayınında tanımlanan offisinal Passiflora türüdür. Bitki sedatif ve anksiyolitik amaçlar için kullanılan birçok bitkisel ilacın bileşiminde yer almaktadır. Bu etkilerin kullanılan ekstrenin kimyasal bileşimine bağlı olduğu belirtilmiştir [14].

Passiflora incarnata'nın toprak üstü kısımları sedatif, anksiyolitik, antispazmodik, analjezik, antikonvülzan, antidiyabetik olarak ve ayrıca boğmacada, bronşitte ve astımda geleneksel olarak kullanılmaktadır. Geleneksel Ayurveda ve Siddha Tip Sistemlerinde antidiyabetik etkisi nedeniyle yer almaktadır. Özellikle $P$. alata ve $P$. incarnata türleri sedatif ve anksiyolitik etkisi nedeniyle insomnia ve anksiyete gibi santral sinir sistemi hastalıklarının tedavisinde kullanıldığı için pek çok farmakope ve monografta kayıtlıdır [5-13]. Cinsin ülkemizde doğal olarak yetişen türü olmamakla beraber güzel ve gösterişli çiçekleri nedeniyle özellikle peyzaj düzenlemelerinde $P$. caerulea (Resim 3, 4) süs amacıyla çit bitkisi olarak yetiştirilmektedir.

\subsubsection{Kimyasal Bileşim}

Passiflora alata yapraklarından flavonoit ve saponin yapısında bileşikler izole edilmiş ve tanımlanmıştır $[15,16]$. Passiflora edulis'te genel olarak sikloartan yapısında triterpenik bileşikler (siklopassifloik asit B ve E, siklopassiflorazit 2, 6, 9 ve 11, siklopassiflorazit 12 ve 13) bulunmaktadır [17]. Benzer Passiflora edulis popülasyonlarına ait örneklerin YPSK ile elde edilen kromatogramlarının da benzer olduğu tespit edilmiştir. Ancak farklı popülasyonlara ait olan örneklerin YPSK verilerinin birbirinden farklı olduğu görülmüştür. P. edulis var. flavicarpa yapraklarından izole edilen altı ana flavonoit (lusenin-2, visenin-2, izoorientin, izoviteksin, luteolin-6-Csinovozit, ve luteolin-6-C-fukozit), P. edulis var. edulis'te bulunamamıştır. Sonuç olarak, P. edulis var. flavicarpa, P. edulis var. edulis’ten tamamen farklı kimyasal içeriğe sahip bir varyete olarak değerlendirilmiştir. Bu varyeteler üzerinde farmakolojik çalışmalar yapılırken dikkat edilmesi gerektiği belirtilmiştir. Bu bulgulara göre $P$. edulis var. flavicarpa'nın Passiflora ekstresi kaynağı olarak kullanılmasının uygun olduğu tespit edilmiştir [18].

Passiflora incarnata'nın toprak üstü kısmının parçalanmış veya kesilmiş, kurutulmuş halini içeren drog, Avrupa Farmakopesi ve Türk Farmakopesi 2017'de Passion Flower (Passiflorae herba, çarkıfelek) adı altında kayıtlıdır. Drog, çiçek ve meyveleri de içerebilir. En az \%1.5 oranında viteksin üzerinden hesaplanmış flavonoit içermesi gerekir [7,8]. Passiflora incarnata yaprak ekstresinin flavonoid (apigenin, luteolin, kersetin, kemferol, C-glikozil flavonoidler, viteksin, izoviteksin, orientin, izoorientin, şaftozit, izoşaftozit ve sivertisin); $\beta$-karbolin alkaloitleri (harman, harmol, harmin, harmalol, harmalin); terpenik bileşikler ( $\alpha$-bergamatol, $\beta$-iyonen, ojenol, izoojenol, trans-anetol, karvon, linalol, benzil alkol ve hekzanol içeren uçucu yağlar); siyanojenik glikozit (ginokardin) ve çeşitli etken madde gruplarına (maltol türevi $\gamma$-benzopren; rafinoz, sukroz, d-fruktoz ve d-glukoz gibi karbonhidratlar) sahip olduğu çeşitli çalışmalarla belirlenmiştir [5,9-11]. 


\subsubsection{Biyolojik Etki}

Passiflora alata'nın toprak üstü kısımlarının \% 60 oranında etanol-su ekstresinin (liyofilize nanokapsülleri) preparatı hazırlanmıştır. Viteksin olarak belirlenen total flavonoid içeriği \% 0.67 olarak hesaplanmıştır. Test çözeltileri farelere oral yoldan uygulanmıştır. $\mathrm{HCl} /$ etanol ile oluşturulmuş akut gastrik ülser modelindeki P. alata nanokapsüllerinin $50 \mathrm{mg} / \mathrm{kg}$ dozda önemli ölçüde gastroprotektif etkiye sahip olduğu gösterilmiştir [19].

Passiflora edulis var. flavicarpa yapraklarından elde edilen sulu liyofilize ekstrenin; farelerde karragenan, bradikinin, histamin veya Substance P ile oluşturulan akciğer zarı iltihabında lökositlerin göçü, miyaloperksidaz (MPO), nitrik oksit (NO) konsantrasyonu ve tümör nekroz faktör-alfa (TNF- $\alpha$ ), interlökin-1 $\beta$ düzeyleri üzerine antienflamatuvar etki mekanizması çalışılmıştır. $P$. edulis ekstresinin, miyeloperoksidaz, proenflamasyon sitokininlerinin ve nitrik oksit düzeylerini inhibe etmede deksametazondan $(0.5 \mathrm{mg} / \mathrm{kg}$, i.p. $)$ daha etkili olduğu gözlenmiştir. Elde edilen bulgulara göre; enflamasyonun oluşmasından yarım saat önce verilen P. edulis ekstresi (250 $\mathrm{mg} / \mathrm{kg}$ ), karragenan ile oluşturulmuş akciğer zarı iltihabı fare modelinde, nötrofilleri ve lökositleri inhibe eden en iyi doz olarak belirlenmiştir [18]. P. edulis'in antidepresan etki gösterdiği kanıtlanmıştır. $P$. edulis'in yaprak ve dallarının alkollü ekstresi 7 gün boyunca $0.4 \mathrm{~mL} / 20 \mathrm{~g}$ dozda intragastral yoldan farelere uygulanmıştır. $P$. edulis'in yaprak ve dallarının fitokimyasal içeriği belirlenmiş ve monomerik maddelerin biyolojik aktiviteden sorumlu olduğu sonucuna varılmıştır [17].

Passiflora incarnata metanollü ekstresinin, diyabetik farelerde önemli derecede antihiperglisemik etkiye sahip olduğu belirlenmiştir. Ekstre ayrıca oral yoldan kan glukoz seviyesi ve vücut ağırlığını düşürmüş, üre glukoz ve lipid yapısı gibi parametrelerde de iyileşme sağlamıştır [5]. P. incarnata'da bulunan harman alkaloidleri geri dönüşlü monoaminoksidaz (MAO)-A inhibitörüdür ve antidepresan etki göstermektedir. $P$. incarnata'nın bileşimindeki bu çeşitli bioaktif maddelerin varlığ , bu bitkinin epilepsinin sonucu olarak ortaya çıkan post-iktal depresyonu iyileştirerek koruma sağlayabileceği hipotezine götürmüştür. Yapılan deneyler sonucunda, ekstre ile tedavi hareketsizlik zamanını ve felç şiddetini önemli ölçüde düşürmüş, ayrıca beyindeki serotonin ve noradrenalin seviyesini korumuştur. $P$. incarnata'nın sulu alkollü ekstresinin pentilentetrazol ile oluşturulmuş felci baskıladığı ve felçle bağlantılı post-iktal depresyonu iyileştirdiği gösterilmiştir [21].

Avrupa ve Türk Farmakopelerinde kayıtlı olan Çarkıfelek, Passiflorae herba Passiflora incarnata bitkisinden elde edilmektedir $[7,8]$ ve geleneksel kullanıma sahiptir. Biyolojik etkileri in vitro, in vivo ve klinik çalışmalarla da tespit edilmiştir $[5,11]$.

\section{Materyal ve yöntem}

Materyal temini için Ankara'da 7 farklı drog satıcısından "çarkıfelek" ya da "passiflora" adı ile örnek aranmış, ancak bu satış yerlerinden üçünden "çarkıfelek" ya da "passiflora" adı ile satışı yapılan 3 örnek satın alınabilmiştir (Tablo 1). Standart olarak Passiflora incarnata'nın kültür (Antalya) formundan elde edilen meyve, morfolojik özelliklerinin tanımlanması için kullanılmıştır (Şekil 9). Piyasadan satın alınan bu üç örnek, Türk (2017) [7] ve Avrupa Farmakopesi'nde [8] tanımlanan drog özelliğine göre morfolojik olarak incelenmiştir.

Tablo 1. Çalışma sırasında kullanılan çarkıfelek (passiflora) örneklerinin temin edildiği yerler ve satışa sunulma şekilleri

\begin{tabular}{|l|l|c|c|}
\hline \multicolumn{1}{|c|}{ Materyal } & \multicolumn{1}{c|}{ Örneklerin alındı̆̆ı yerler } & Piyasada bulunuş şekli & Resim no \\
\hline Örnek 1 & Yenimahalle & Açıkta & 5 \\
\hline Örnek 2 & Kızılay & Paket halinde & 6 \\
\hline Örnek 3 & Kızılay & Paket halinde & 7 \\
\hline
\end{tabular}

Çalışmada "çarkıfelek" ya da "passiflora" adı ile satın alınan örneklerin hepsi meyve kısmı olduğu için standart numune olarak Passiflora incarnata'nın meyvesi (özel üretim, Antalya) karşılaştırma için kullanılmıştır. Piyasadan satın alınan örneklerin teşhisi için Türkiye Florası [22] ve pl@ntNet [23] uygulamasından yararlanılmıştır.

\section{Bulgular}

Ankara piyasasında 7 farklı drog satıcısına gidilmiş, ancak "çarkıfelek" ya da "passiflora" adıyla piyasada var olan 3 örnek satın alınabilmiştir. 

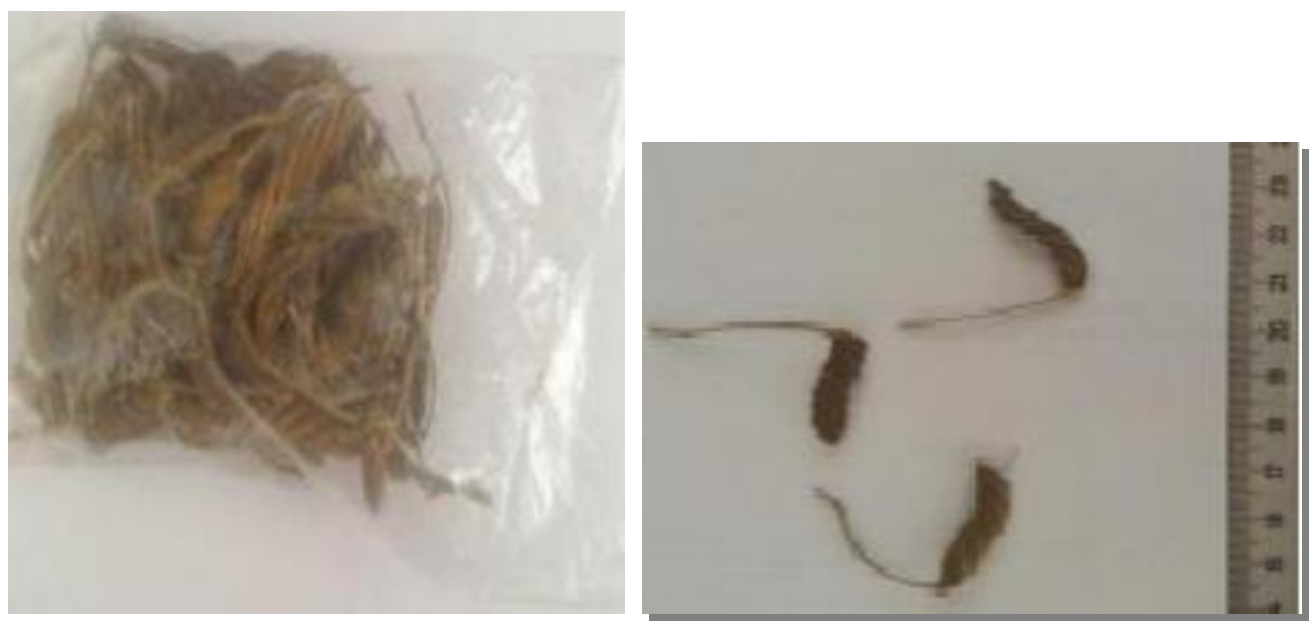

Resim 5. Örnek 1. Piyasadan (Yenimahalle) satın alınan “çarkıfelek kökü” olarak açıkta satılan numune A. Naylon torba içinde, B. Caiophora lateritia Klotzsch (Loasaceae) meyveleri olarak tanımlanmıştır.

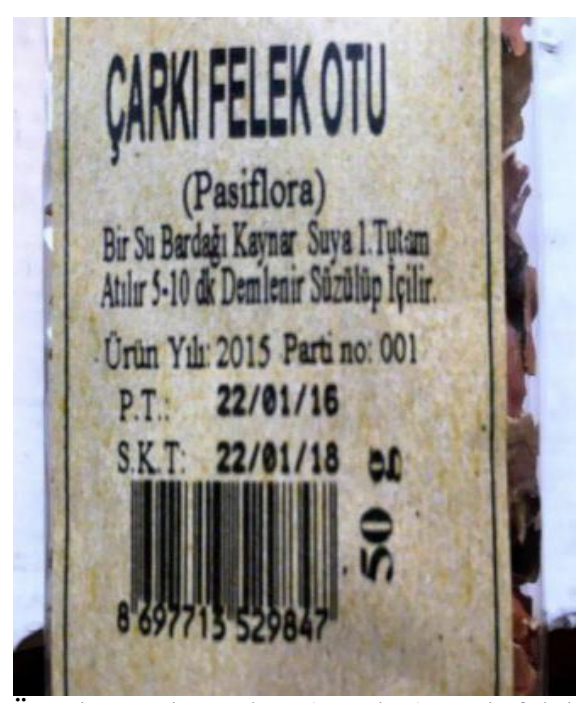

Resim 6. Örnek 2. Piyasadan (Kızılay) çarkıfelek otu (passiflora) adı ile satın alınan paketli numune.

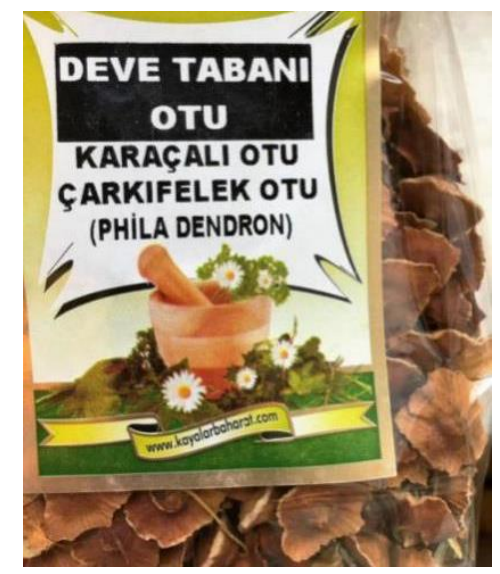

Resim 7. Örnek 3. Piyasadan (Kızılay) çarkıfelek otu adı ile satın alınan paketli numune.

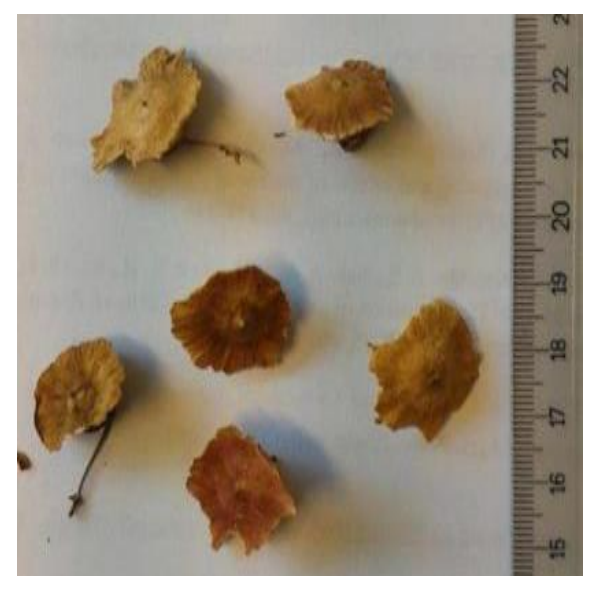

Resim 8. Paliurus spina-christi Miller (karaçall; Rhamnaceae) meyveleri

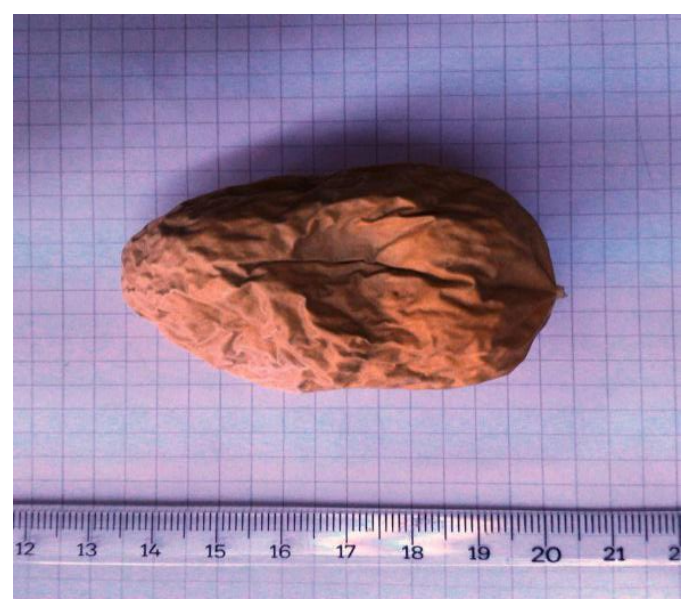

Resim 9. Passiflora incarnata meyvesi (özel üretim, Antalya). 
Resimlerde de görüldüğü gibi (Şekil 5-8) piyasadan temin edilen hiçbir örnek Passiflora incarnata bitkisine ait drog örnekleri değildir. Bu örneklerden Yenimahalle'den temin edilen örnek (Örnek 1, Resim 5A, B) açıkta paketlenmemiş olarak "çarkıfelek kökü" adı ile satılmaktadır. Örnek satın alma sırasında naylon bir torbaya koyulup halka sunulmaktadır (Resim 5A). Kök olarak satılan bitki kısmının ülkemizde yetişmeyen bir bitkiye ait meyve kısımları olduğu belirlenmiștir. Meyvelerin burulmuş halde olması "çarkıfelek" uzun ve koyu renkli olması ise "kök" olarak yorumlanması nedeniyle bu isimle satıldığını düşündürmüştür. "Çarkıfelek kökü” olarak satılan bu drog ülkemize ait bir bitkiden elde edilmemektedir. Droğun elde edildiği bitki Arjantin, Brezilya ve Paraguay gibi orta And Dağları bölgesine ait Caiophora lateritia bitkisidir ve satın alınan örnekler bu bitkinin meyveleri olarak tespit edilmiştir $[23,24]$. Örnek 2 ve 3 ise Paliurus spina-christi (karaçalı) meyveleridir [22] ve paketlenmiş halde "çarkıfelek otu" adıyla piyasada bulunmakta, halka sakinleştirici olarak tedavi edici amaçla satılmaktadır.

\section{Sonuçlar ve tartışma}

Çalışmamızda Passiflora cinsine ait (Passifloraceae) tıbbi özellikleri nedeniyle hem geleneksel hem de farmakolojik kullanımı olan üç tür (Passiflora alata, . edulis ve $P$. incarnata), son yıllarda yapılan çalışmalar 1şı̆̆ında incelenmiş ve bulgular derlenmiştir. Ayrıca başkent Ankara piyasasında tedavi amacıyla satışı yapılan örnekler, Avrupa Farmakopesi ve Türk Farmakopesi 2017'de Passion Flower (Passiflorae herba, çarkıfelek) adı altında kayıtlı olan drog tanımı ile morfolojik özellikleri açısından karşılaştırılmak üzere satın alınmıştır. Her iki farmakopeye göre drog, P. incarnata'nın toprak üstü kısmının (çiçek ve meyveleri de içerebilir) parçalanmış veya kesilmiş, kurutulmuş halini tanımlar [7,8]. Avrupa İlaç Kurumu (EMA, European Medicines Agency) monograflarında P. incarnata herbası, oral kullanım için tıbbi çay veya katı (tablet, kapsül) ya da sıvı dozaj [etanollü ya da etanol:gliserin:su (54:5:60) ekstresi] formunda ekstreleri kayıtlıdır. Ayrıca tek başına ya da kombine preparatları halinde orta şiddetli zihinsel stres ya da uykusuzluk halinde kullanılması önerilmektedir. Tıbbi çay halinde 2 g'lık poşetlerde (Resim 10) hazırlanıp HPMC (Committee on Herbal Medicinal Products) monograflarına göre kullanılması önerilmektedir [9].
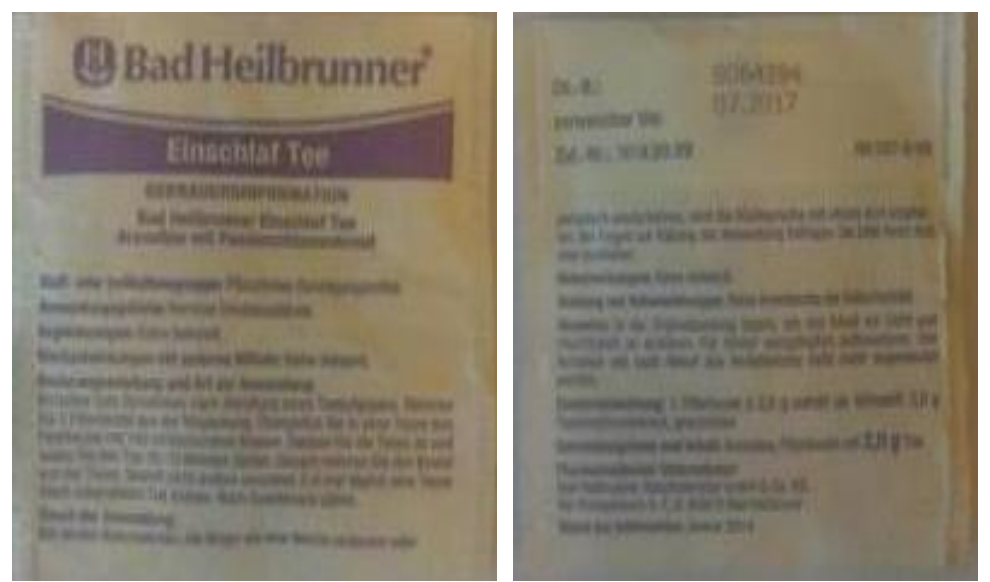

Resim 10. Almanya'da eczanelerde endikasyon belirtilerek satılan Passiflora incarnata tıbbi çay paketi

Çalışmamızın deneysel olarak yürütülen kısmında, ülkemiz piyasasında özellikle Başkent Ankara'da doğrudan tedavi amacıyla kullanılmak üzere satışa sunulmuş olan "passiflora ya da çarkıfelek” adıyla örnekler temin edilmiştir. Örnek temini sırasında tedavi amacıyla piyasada bulunan örneklerin açıkta ya da paketlenmiş halde satışa sunulduğu tespit edilmiştir. Satın alınan örnekler üzerinde yürüttüğümüz morfolojik çalışmalar sonucunda, olması gerekenden tamamen farklı bitkilerden elde edilen drogların Ankara piyasasında tedavi edici değeri nedeniyle satıldığ belirlenmiştir. Ayrıca tıbbi amaçla kullanılan bitki kısmı olarak kök (Yenimahalle - aslında bir meyve; açıkta satılıyor) (Resim 5) ve meyvelerin [Kızılay - Paliurus spina-christi meyveleri [18]; paketlenmiş halde (Resim 6, 7)] önerildiği ve satıldığ 1 tespit edilmiştir. Nisan 2016'ya kadar piyasada çeşitli ekstreleri halinde de ulaşılabilen passiflora preparatları, bu tarihten sonra Sağlık Bakanlığı tarafından eczaneler dışında satışının yapılmasına izin vermediği için temin edilememiştir.

$\mathrm{Bu}$ örneklerden Yenimahalle'den temin edilen örnek “çarkıfelek kökü” adıyla satılmakta ve açıkta, paketlenmemiş olarak halka sunulmaktadır (Şekil 5. A-B). Kök olarak satılan bitki kısmının ülkemizde yetişmeyen bir bitkiye ait meyve kısımları olduğu belirlenmiştir. Meyvelerin burulmuş halde olması "kök" olarak yorumlanmasına neden olduğu için bu isimle satıldığını düşündürmüştür. "Çarkıfelek kökü” olarak satılan bu drog ülkemizde yetişmeyen Caiophora lateritia bitkisinin meyveleridir [23, 24]. Bu türün tıbbi amaçla kullanıldığına dair bilgiye ulaşılamamıştır.

Ankara piyasasından temin ettiğimiz her üç örnek de Passiflora cinsine ait değildir. 3 nolu örnek (Resim 7) paketi üzerinde Phila dendron Latince, karaçalı otu ve çarkıfelek Türkçe isimleri yer almaktadır. Phila dendron yapılan inceleme sonucunda bilimsel bitki ismi olarak bulunamamıştır [25]. Karaçalı ismi ülkemizde genellikle Paliurus spina- 
christi bitkisine verilen yerel bir isimdir. Bu meyveler aslında Rhamnaceae familyasında bir bitki olan P. spinachristi'ye aittir [22].

Ülkemizde süs amacıyla bahçe kenarlarında yetiştirilen cinsin tek temsilcisi Passiflora caerulea'dır. Bunun dışında $P$. incarnata türünün de Antalya ve Muğla'da tropikal meyve yetiştiriciliği yapan üreticiler tarafindan küçük bir alanda kültürünün yapıldığına dair bilgimiz vardır (Şekil 9).

Çalışma sonucunda elde ettiğimiz bulgular, tedavi amacıyla satılan bitki kaynaklı drogların, bilimsel botanik teşhislerinin doğru yapılması gerektiğini ve ancak doğru bilimsel isme sahip bitkilerden elde edilen doğru bitki kısımlarının hastalıklardan korunmak, sağlığı sürdürmek veya yeniden kazanmak amacıyla kullanılmalarının önemini ve gerekliliğini bir kez daha göstermiştir. Doğada yetişen türlerin toplanıp kurutulması durumunda doğru bitkinin toplanıp toplanmadığı önemli bir sorundur. Drog elde edilmesinde kullanılacak tıbbi bitkilerin ve bitki kısımlarının öncelikle botanik standardizasyonunun yapılması gereklidir. Çalışma, ülkemiz piyasasında (Başkent Ankara) "çarkıfelek, passiflora" adı ile satışa sunulmuş olan örneklerin, Türk (2017) ve Avrupa Farmakopesi'nde [7,8] verilen bitki ve drog özelliklerine uymadığını ve sonuçta da tıbbi kullanımının halk sağlığı açısından güvenilir olmayacağını kanıtlamıştır.

Çalışmamız piyasada yerel isimle ve tıbbi amaçla kullanılması için satışa sunulan bitki kısımlarının doğru bitkiden elde edilmediği gibi doğru bitki kısımları da olmadığı̆ı göstermiştir. Doğru bitkiden elde edilen ve doğru bitki kısmı kullanılan drog, tedavi değerine sahiptir ve insan sağlı̆̆ında güvenle kullanılabilir. Piyasamızdan satın aldığımız bu örneklerin hiçbir tıbbi değeri yoktur ve insan sağlığında kullanılması satışa sunulduğu amaçlar için uygun değildir. Avrupa ülkelerinde olduğu gibi ülkemizde de tıbbi amaçla kullanılacak olan bitkisel drogların standardizasyonunun sağlanması, menşei belli tohumlardan İyi Tarım Uygulamaları ile elde edilmesi ve bundan sonra piyasaya sunulması gerekmektedir. Bu konuda yerli üreticilerin bilgilendirilmesi ve teşvik edilmesi ülkemizin standardizasyonu sağlanmış tıbbi bitkileri ve bu bitkilerden elde edilecek drogları iç ve dış piyasaya sunması açısından önem taşımaktadır.

\section{Kaynaklar}

[1] Cerqueira-Silva, C.B.M., Jesus, O.N., Santos, E.S.L., Corrêa, R.X., Souza, A.P. (2014). Genetic Breeding and Diversity of the Genus Passiflora: Progress and Perspectives in Molecular and Genetic Studies. International Journal of Molecular Sciences, 15(8), 14122-14152. https://doi:10.3390/ijms150814122

[2] Cerqueira-Silva, C.B.M., Faleiro, F.G., Jesus O.N., Santos, E.S.L., Souza, A.P. (2016). The genetic diversity, conservation and use of passion fruit (Passiflora spp.). Chapter 5, Series Book: Sustainable Developments and Biotechnology Individual Book: Erosion and Biodiversity. http://dx.doi.org/10.1007/978-3-319-25954-3_5

[3] Mezzonato-Pires, A. C., Milward-de-Azevedo, M.A., Mendonça, C.B.F., Gonçalves-Esteves, V. (2019). Taxonomic notes on species of Passiflora subgenus Astrophea (Passifloraceae ss). Acta Botanica Brasilica, 33(1), 149-152. https://doi.org/10.1590/0102-33062018abb0405

[4] Nunes, T. (2009). Neotropical Passifloraceae. In: Milliken, W., Klitgård, B. \& Baracat, A. (2009 onwards), Neotropikey - Interactive key and information resources for flowering plants of the Neotropics. http://www.kew.org/science/tropamerica/neotropikey/families/Passifloraceae.htm

[5] Gupta, R.K., Kumar, D., Chaudhary, A.K., Maithani, M., Singh, R. (2012). Antidiabetic activity of Passiflora incarnata Linn. in streptozotocin-induced diabetes in mice. Journal of Ethnopharmacology, 139, 801-806. DOI: 10.1016/j.jep.2011.12.021

[6] Miroddi, M., Kalapai, G., Navarra, M., Minciullo, P.L., Gangemi, S. (2013). Passiflora incarnata L.: Ethnopharmacology, clinical application, safety and evaluation of clinical trials. Journal of Ethnopharmacology, 150, 791-804. DOI:10.1016/j.jep.2013.09.047

[7] TF (2017). Türk Farmakopesi 2017. T.C. Sağlık bakanlığı, Türkiye İlaç ve Tibbi Cihaz Kurumu. Genel Monograflar, Cilt III A-G, s. 1885. Art1 6 Reklam Mattbaa Ltd. Şti. Ankara.

[8] European Pharmacopoeia, Council of Europe (2013). 10th ed., Strasbourg: European Directorate for the Quality of Medicines \& HealthCare.

[9] EMA (European Medicines Agency) EMA/ HMPC/ 669738/ 2013, Assesment report on Passiflora incarnata L., herba.www.ema.europa.eu/.../en_GB/document_library/Herbal_HMPC_assessment_report/2014/06/WC5001689 64.pdf - 187k - $2014-06-18$

[10] ESCOP (2003). ESCOP Monographs. The scientific Foundation for Herbal Medicinal Prducts. Second Ed. Cmpletely revised and expanded. Thieme.

[11] Koca Çalışkan U. (2017). FFD Monografları, Bitkiler ve Etkileri. Eds. Demirezer, Ö., Ersöz, T., Saraçoğlu, İ., Şener, B., Köroğlu, A., Yalçın, F. N., Akademisyen Kitabevi, Ankara.

[12] DHA (1978). Deutshes Homopathisches Arzneibuch, 1st ed. Deutscher Apotheker Verlag, Stuttgart, Germany. 
[13] HPUS (1992). The Homeopathic Pharmacopoeia of the United States. Pharmacopoeia Convention of the American Institute of Homeopathy, Arlington, USA.

[14] Braga, A., Stein, A.C., Stolz, A.D., Dallegrave, E., Buffon, A., Rego, J.,... Rates, S. M. K. (2013). Repeated administration of an aqueous spray-dried extract of the leaves of Passiflora alata Curtis (Passifloraceae) inhibits body weight gain without altering mice behavior. Journal of Ethnopharmacology, 145, 59-66.

[15] Ulubelen, A., Oksuz S., Mabry T. J., Dellamonica G., Chopin J. (1982). C-Glycosylflavonoids from Passiflora pittieri, P. alata, P. ambigua and Adenia mannii. J Nat Prod 45: 783-783.

[16] Doyama, J.T., Rodriguesa, H.G., Novellia, E.L.B., Ceredab E., Vilegas W. (2005). Chemical investigation and effects of the tea of Passiflora alata on biochemical parameters in rats. Journal of Ethnopharmacology, 96, 371374.

[17] Wang, C., Xu, F. Q., Shang, J. H., Xiao, H., Fan, W. W., Dong, F. W., Zhou, J. (2013). Cycloartane triterpenoid saponins from water soluble of Passiflora edulis Sims. and their antidepressant-like effects. Journal of Ethnopharmacology, 148, 812-817.

[18] Li, H., Zhou, P., Yang, Q., Shen, Y., Deng, J., Li, L., Zhao, D. (2011). Comparative studies on anxiolytic activities and flavonoid compositions of Passiflora edulis 'edulis' and Passiflora edulis 'flavicarpa'. Journal of Ethnopharmacology, 133, 1085-1090.

[19] Wasicky A., Hernandes L. S., Neto A. V., Moreno P. R. H., Bacchi E.F., Kato E. T. M., Yoshida M. (2015). Evaluation of gastroprotective activity of Passiflora alata. Revista Brasileira de Farmacognozia, 25, 407-412.

[20] Montanher, A. B., Zucolotto, S.M., Schenkel, E.P., Fröde, T.S. (2007). Evidence of anti-inflammatory effects of Passiflora edulis in an inflammation model. Journal of Ethnopharmacology, 100, 281-288.

[21] Singh, B., Singh, D., Goel, D.K. (2012). Dual protective effect of Passiflora incarnata in epilepsy and associated post-ictal depression. Journal of Ethnopharmacology, 139, 273-279.

[22] Davis, P.H. (1967). "Paliurus" In Flora of Turkey and The Aegean Islands. Vol, 2 eds. Davis, P.H., Cullen, J., Coode, M.J.E. Edinburgh University Press. Edinburgh.

[23] PlantNet. (2020). Pl@ntNet app. http://plantnet.org

[24] Slanis, A., Perea, M.C., Grau, A. (2016). Taxonomic revision of the genus Caiophora (Loasaceae) from Argentina: A new species C. sleumerii. DARWINIANA, nueva serie, 4(2). 138-191.

[25] theplantlist.org (2021). http://www.theplantlist.org/tpl1.1/search?q=Phila+dendron. 